\title{
Originals
}

\section{Non-enzymatic glycosylation of skin collagen in patients with Type 1 (insulin-dependent) diabetes mellitus and limited joint mobility}

\author{
T.J. Lyons and L. Kennedy \\ Sir George E. Clark Metabolic Unit, Royal Victoria Hospital, Belfast, Northern Ireland
}

\begin{abstract}
Summary. Forearm skin biopsies were obtained from diabetic subjects with and without limited joint mobility, and from non-diabetic control subjects. Collagen purified from these samples was assayed for non-enzymatic glycosylation. The level in all diabetic patients was significantly greater than that in control subjects $(p<0.001)$, but those diabetic patients with limited joint mobility had a level of collagen glycosylation similar to that in those with normal joints $(15.3 \pm 1.3$ and $16.5 \pm 1.3 \mathrm{nmol}$ fructose $/ 10 \mathrm{mg}$ protein, respectively; mean \pm
\end{abstract}

SEM). Glycosylation of collagen in the diabetic patients correlated with glycosylated haemoglobin measured at the time of skin biopsy $(r=0.60)$. These results do not support the hypothesis that non-enzymatic glycosylation of collagen, as reflected by the ketoamine link, plays an important role in the development of limited joint mobility in diabetes.

Key words: Collagen, non-enzymatic glycosylation, limited joint mobility, haemoglobin $A_{1}$, ketoamine link.
The non-enzymatic adduction of glucose to receptive amino groups - non-enzymatic glycosylation - is an essentially irreversible process which affects many circulating and structural body proteins. The extent of such glycosylation of a protein in vivo depends on two main factors - the rate of turnover of the protein and the average glucose level to which it is exposed. For this reason the level of non-enzymatic glycosylation of most proteins is approximately two to four times higher in diabetic than non-diabetic subjects, and there is speculation that the process may have pathophysiological effects relevant to the long-term complications of diabetes [1-4].

Limited joint mobility, mainly affecting the small joints of the hands, has been reported to occur in $8.6-36.5 \%$ of patients with Type 1 (insulin-dependent) diabetes [5-8], and may also be seen in Type 2 (non-insulin-dependent) diabetes [9]. In several of these studies there is a clear correlation between the presence of limited joint mobility and retinopathy, especially the proliferative type $[5,8,9]$. The exact cause of limited joint mobility in diabetes is not known but it has been suggested that a structural alteration in collagen, perhaps related to glycosylation, may play a part $[2,10,11]$. In view of the association between limited joint mobility and retinopathy, elucidation of the processes involved in the evolution of the former may also shed light on the pathogenesis of chronic diabetic complications in general.
In this study we have investigated the glycosylation of skin collagen from diabetic patients with and without limited joint mobility.

\section{Subjects and methods}

\section{Subjects}

Patients attending the diabetes clinics of the Royal Victoria Hospital, Belfast were examined for limited joint mobility by the method outlined by Rosenbloom et al. [5]. Only patients with clearly normal joint mobility and those with either moderate limitation (involvement of three or more interphalangeal joints) or severe limitation (moderate limitation combined with bilateral large joint or cervical spine involvement) were included in the study. Patients with equivocal changes or only mild limitation were excluded. Examination findings were confirmed by at least two observers. Thirty-six patients with Type 1 diabetes are included in the study. After the experimental nature of the study had been explained and consent obtained, an elliptical full thickness skin biopsy (approximately $1.0 \times 0.5 \mathrm{~cm}$ ) was taken, under $2 \%$ lignocaine local anaesthetia, from the medial aspect of the forearm. Biopsies were also obtained from three healthy non-diabetic volunteers and at autopsy from seven patients who had died of acute illnesses. These seven were not known to be diabetic and had one or more normal plasma glucose measurements during the terminal illness. The study was approved by the Ethical Committee of the Royal Victoria Hospital, Belfast.

\section{Methods}

Each skin biopsy was immediately frozen and kept at $-70^{\circ} \mathrm{C}$ before preparation for assay. After thawing, the skin was scraped to remove keratin and subcutaneous fat. It was then washed in distilled water 
Table 1. Characteristics of diabetic patients and normal subjects

\begin{tabular}{|c|c|c|c|}
\hline & \multicolumn{2}{|c|}{ Diabetic patients with: } & \multirow{2}{*}{$\begin{array}{l}\text { Control } \\
\text { subjects } \\
(n=10)\end{array}$} \\
\hline & $\begin{array}{l}\text { Normal } \\
\text { joints } \\
(n=24)\end{array}$ & $\begin{array}{l}\text { Limited joint } \\
\text { mobility } \\
(n=12)\end{array}$ & \\
\hline $\operatorname{Sex}(M: F)$ & $10: 14$ & $9: 3$ & $3: 7$ \\
\hline Age (years) & $41.6 \pm 3.2$ & $49.1 \pm 3.9$ & $46.9 \pm 6.2$ \\
\hline $\begin{array}{l}\text { Age at onset of diabetes } \\
\text { (years) }\end{array}$ & $24.6 \pm 2.9$ & $22.4 \pm 3.9$ & \\
\hline $\begin{array}{l}\text { Duration of diabetes } \\
\text { (years) }\end{array}$ & $17.0 \pm 2.7$ & $26.7 \pm 2.7^{\mathrm{a}}$ & \\
\hline $\mathrm{HbA}_{1}(\%)$ & $10.9 \pm 0.6$ & $10.8 \pm 0.5$ & \\
\hline
\end{tabular}

Results are mean $\pm \mathrm{SEM}$

${ }^{a} p<0.05$, compared with diabetic patients with normal joints

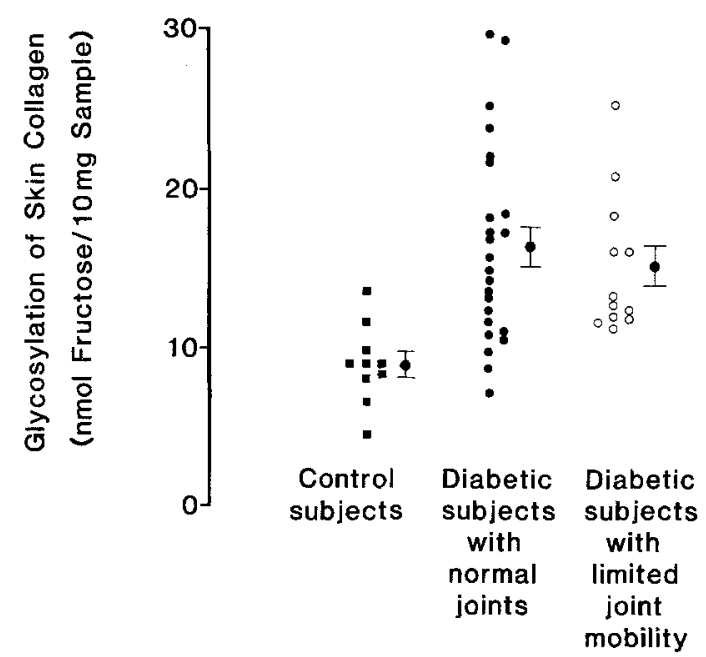

Fig.1. Levels of non-enzymatically glycosylated skin collagen. Bars indicate mean $\pm S E M$ for each group

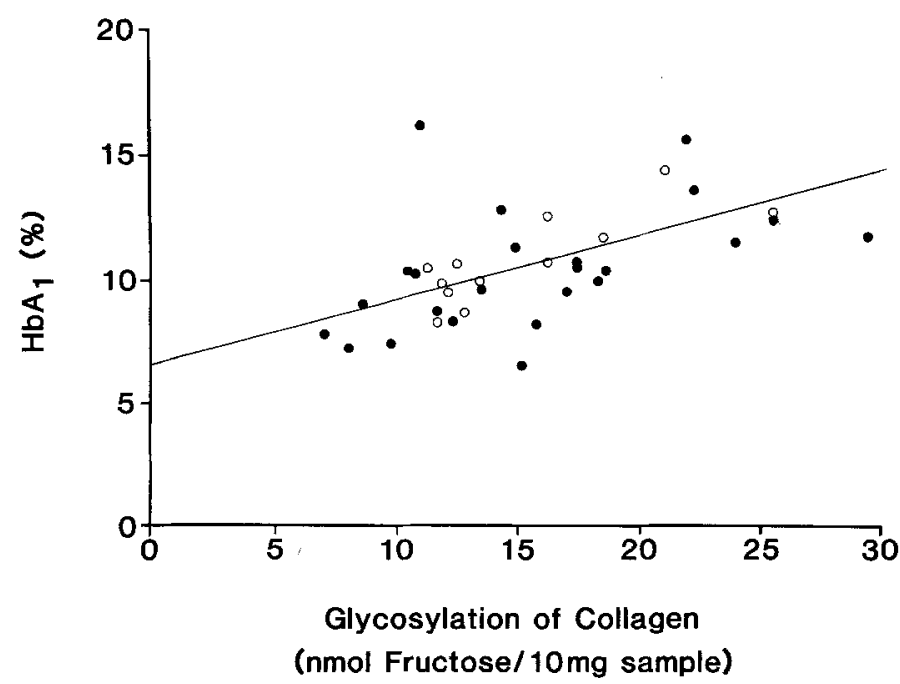

Fig. 2. Correlation between glycosylated collagen and $\mathrm{HbA}_{1}$ in diabetic patients with $(O)$ and without $(\bullet)$ limited joint mobility, data combined $(r=60)$. See text for details of regressions and extracted by agitating sequentially at $4{ }^{\circ} \mathrm{C}$ in $1.0 \mathrm{~mol} / 1 \mathrm{NaCl}$, hexane and $0.5 \mathrm{~mol} / 1$ acetic acid, for $24 \mathrm{~h}$ each, to remove soluble proteins and remaining fat $[12,13]$. Further washing in distilled water was followed by lyophilisation. This resulted in a yield of $20-30 \mathrm{mg}$ of insoluble protein from each biopsy and hydroxyproline estimation [14] indicated that samples contained approximately $80 \%$ collagen (range in 12 samples, 76-88\%). Measurement of non-enzymatic glycosylation was by weak acid hydrolysis, adapted from the method of Fluckiger and Winterhalter [15]. Approximate $10-12 \mathrm{mg}$ pieces of lyophilised material (accurately weighed) were added to $650 \mu \mathrm{l}$ distilled water and $750 \mu \mathrm{l} 1.0 \mathrm{~mol} / \mathrm{l}$ oxalic acid. Hydrolysis was carried out for $1 \mathrm{~h}$ in an autoclave (model ST19, Arnold \& Son, Basildon, Essex, UK) at $121{ }^{\circ} \mathrm{C}$ and $1.05 \mathrm{~kg} / \mathrm{cm}^{2}[16,17]$. The amount of 5 hydroxymethylfurfural (5-HMF) yielded was quantitated by reaction with thiobarbituric acid and measurement of absorption at $443 \mathrm{~nm}$. For every sample a blank was run, in which a similar weight of lyophilised material was incubated with $400 \mu \mathrm{l} 0.1 \mathrm{~mol} / 1 \mathrm{NaBH}_{4}$ and $100 \mu \mathrm{l}$ distilled water for $15 \mathrm{~min}$ and then quenched with $150 \mu \mathrm{l}$ reagent grade acetone before hydrolysis. This reduces the ketoamine link between glucose and protein to a non-reacting form [18]. During each assay run, a standard curve was constructed from fructose solutions of varying concentrations which were hydrolysed and reacted with thiobarbituric acid in the same fashion as the tissue samples. Fructose is hydrolysed to 5-HMF and hence this allows for small differences in the efficiency of the hydrolysis between assay runs [19]. Specific glycosylation of collagen was expressed as nmol fructose $/ 10 \mathrm{mg}$ protein. Using collagen, prepared as outlined above, from skin samples obtained from a below-knee amputation in a diabetic patient with peripheral vascular disease, an intra-assay coefficient of variation of $10.3 \%(n=12)$ and a between-assay coefficient of variation of $17.7 \%(n=11)$ were obtained for the complete procedure.

Glycosylated haemoglobin $\left(\mathrm{HbA}_{1}\right)$ was measured in blood samples (drawn into EDTA) obtained from the diabetic patients at the time of skin biopsy. Red cells were incubated in $0.154 \mathrm{~mol} / 1 \mathrm{NaCl}$ for $18 \mathrm{~h}$ to remove labile $\mathrm{HbA}_{1}$ [20], and stable $\mathrm{HbA}_{1}$ was measured by agar gel electroendosmosis [21] (Corning, Halstead, Essex, UK), the method routinely used at our clinics. The normal range in non-diabetic subjects in our laboratory is $3.6-7.2 \%$, and the coefficient of variation is $1.6 \%$ within and $6.4 \%$ between assay.

\section{Statistical analysis}

Results are expressed as mean \pm SEM. Comparisons were made with the unpaired Student's t-test and correlations by linear regression analysis.

\section{Results}

Twenty-four diabetic patients had normal movement in their joints and 12 had limited joint mobility - in nine this was moderate and in three severe. Age, sex, age at onset, duration of diabetes and $\mathrm{HbA}_{1}$ levels are shown in Table 1. Only duration of diabetes differed significantly between the two diabetic groups $(p<$ 0.005 ).

The levels of skin collagen glycosylation are shown in Figure 1. Compared to control subjects the diabetic patients, considered either in two groups or collectively, had a significantly increased level of collagen glycosylation $(p<0.001)$. There was no significant difference in collagen glycosylation between diabetic patients with and without limited joint mobility $(15.3 \pm 1.3$ versus $16.5 \pm 1.3 \mathrm{nmol}$ fructose $/ 10 \mathrm{mg}$ protein, respectively). When diabetic patients with normal joint movement and duration of diabetes $\geqslant 10$ years $(n=16)$ only were 
considered, to give a duration similar to that in the group with limited joint mobility $(23.4 \pm 3.0$ years $)$, the collagen glycosylation was also similar $(16.0 \pm 1.5 \mathrm{nmol}$ fructose $/ 10 \mathrm{mg}$ protein).

The clear correlation between collagen glycosylation and $\mathrm{HbA}_{1}$ in the 36 diabetic patients is shown in Figure $2(r=0.60, p<0.001)$. The correlation between these two parameters was similar in those with $(r=0.64)$ and without $(r=0.60)$ limited joint mobility. In the diabetic patients collagen glycosylation did not correlate with either duration of diabetes or age.

\section{Discussion}

Investigation of possible structural or biochemical abnormalities involved in chronic diabetic complications is hampered in man, not least because it is difficult or ethically unjustifiable to obtain tissue from those organs directly involved - notably the eyes and the kidneys. Even when tissue may be made available in patients with severe complications - for example, at renal transplant, vitrectomy or autopsy - there remains the problem of adequate control tissue from the diabetic subject free of complications. It now seems that limited joint mobility is another chronic complication of diabetes evolving alongside retinopathy [5, 8,9], nephropathy [5] and probably also neuropathy [22]. Many of the patients with limited joint mobility have thickening and contracture of palmar tendons and also thickening of skin; it thus seems reasonable to suspect that an abnormality of collagen may be present. We therefore believe that our study may be unique in that it examines, in patients with and without a particular chronic diabetic complication, an abnormality of a protein which may be intimately involved in the development and clinical manifestations of that complication.

The hypothesis that non-enzymatic glycosylation may underlie the evolution of chronic diabetic complications is attractive, as it would fit in with the considerable evidence from animal studies, and the widely-held belief among clinicians, that there is some link between the degree of long-term glycaemia and complications. Increased glycosylation of collagen in vivo has been correlated with decreased solubility, elasticity and sensitivity to protease digestion [13], and increased thermal stability [23]. Incubation of collagen with glucose in vitro also inhibits its degradation by proteases [24]. These observations are consistent with an increase in collagen cross-linking in diabetes. Furthermore in three patients with severe joint limitation, Buckingham et al., using a technique similar to ours, observed a considerable increase in hexose bound to skin protein in ketoamine linkage as compared with non-diabetic controls, though there was no comparison with diabetic patients free of joint limitation [10].

Our data do not support the concept that non-enzymatic glycosylation, at least as reflected by the keto- amine link, is central to the development of limited joint mobility. Patients with clinically normal joints had just as high levels of collagen glycosylation as those with quite advanced degrees of joint limitation. We chose to examine collagen from forearm skin as this was acceptable to patients and we did not consider it practical, or ethical, to attempt to obtain biopsies from fingers or joints. We cannot know whether collagen from those sites, where the clinical abnormality is most obvious, would have yielded completely similar results, but we have no real reason to believe the conclusions would be different. The ketoamine link between glucose and amino groups, which was measured in our collagen glycosylation assay, is the first stable product of the non-enzymatic glycosylation reaction. It is known to undergo further dehydration, rearrangement and cleavage reactions resulting in final products that are highly crosslinked, insoluble, pigmented polymers called melanoidins $[25,26]$. This may help to explain the good correlation observed between $\mathrm{HbA}_{1}$ and glycosylated collagen (Fig.2). Since collagens are among the longest lived proteins in the body one would expect collagen glycosylation to reflect glycaemia over a period of many months. However, if the ketoamine link undergoes further rearrangement in vivo after a period of time not too dissimilar from the life span of the average erythrocyte, then the measured glycosylation of collagen might well reflect glycaemia for a similar period of time as $\mathrm{HbA}_{1}$, which is known to respond to improved blood glucose control within 6-10 weeks [27, 28]. The corollary of that hypothesis is that if the ketoamine link is relatively short lived it is less likely to be involved in the development of chronic complications than the subsequent products (melanoidins), about which much less is known in vivo.

In conclusion, our data highlight the importance of including adequate and appropriate controls in clinical studies, before attributing undue pathophysiological significance to any biochemical parameter which is known to be altered or increased in diabetic as compared with non-diabetic subjects. Although our results do not support the concept that the early products of non-enzymatic glycosylation play an important part in the development of limited joint mobility seen in diabetes, the possibility that subsequent degradation of the ketoamine link may play a role remains to be investigated.

Acknowledgements. We wish to thank Professor K. D. Buchanan, Department of Medicine, Queen's University Belfast for provision of laboratory facilities; E. Elder and A. McMaster for their expert laboratory assistance; and P. Robinson for preparing the manuscript.

\section{References}

1. Bunn HF, Gabbay KH, Gallop PM (1978) The glycosylation of hemoglobin: relevance to diabetes mellitus. Science 200: 21-27

2. Monnier VM, Cerami A (1982) Non-enzymatic glycosylation and browning of proteins in diabetes. Clin Endocrinol Metab 11: $431-452$ 
3. Kennedy L, Baynes JW (1984) Non-enzymatic glycosylation and the chronic complications of diabetes: an overview. Diabetologia 26: $93-98$

4. Peterson CM, Jones RL (1977) Minor hemoglobins, diabetic "control" and diseases of post-synthetic protein modification. Ann Int Med 87: 489-491

5. Rosenbloom AL, Silverstein JH, Lezotte DC, Richardson K, McCallum M (1981) Limited joint mobility in childhood diabetes mellitus indicates increased risk for microvascular disease. N Engl J Med 305: 191-194

6. Traisman HS, Traisman ES, Marr TJ, Wise J (1978) Joint contractures in patients with juvenile diabetes and their siblings. Diabetes Care 1:360-361

7. Brice JEH, Johnston DI, Noronha JL (1982) Limited finger joint mobility in diabetes. Arch Dis Child 57:879-881

8. Kennedy L, Beacom R, Archer DB, Carson DJ, Campbell SL, Johnston PB, Maguire CJ (1982) Limited joint mobility in Type 1 diabetes mellitus. Postgrad Med J 58: 481-484

9. Lawson PM, Maneschi F, Kohner EM (1983) The relationship of hand abnormalities to diabetes and diabetic retinopathy. Diabetes Care 6: 140-143

10. Buckingham BA, Uitto J, Sandborg C, Keens T, Kaufman F, Landing B (1981) Scleroderma-like syndrome and the non-enzymatic glycosylation of collagen in children with poorly controlled insulin dependent diabetes. Pediatr Res; part 1: 626 (Abstract)

11. Knowles HB (1981) Joint contractures, waxy skin and control of diabetes. N Engl J Med 305: 217-219

12. Schnider SL, Kohn RR (1980) Glucosylation of human collagen in aging and diabetes mellitus. J Clin Invest 66: 1179-1181

13. Schnider SL, Kohn RR (1981) The effects of age and diabetes mellitus on the solubility and non-enzymatic glucosylation of human skin collagen. J Clin Invest 67: 1630-1635

14. Stegemann H, Stalder K (1967) Determination of hydroxyproline. Clin Chim Acta 18: 267-273

15. Fluckiger R, Winterhalter KH (1976) In vitro synthesis of hemoglobin $A_{1 c}$. FEBS Lett $71: 356-360$

16. Parker KM, England JD, DaCosta J, Hess RL, Goldstein DE (1981) Improved colorimetric assays for glycosylated hemoglobin. Clin Chem 27: 669-672

17. Elder E, Kennedy L (1983) Rapid accurate assay of non-enzymatically glycosylated serum proteins. Diabetologia 24: 70-71

18. Thorpe SR, Baynes JW (1982) Non-enzymatic glycosylation of proteins in vitro and in vivo. In: Horowitz MI, Pigman W (eds)
The glycoconjugates, Vol3. Academic Press, New York, pp 113-131

19. Pecoraro RE, Graf RJ, Halter JB, Beiter H, Porte D Jr (1979) Comparison of a colorimetric assay for glycosylated hemoglobin with ion-exchange chromatography. Diabetes 28: 1120-1125

20. Goldstein DE, Peth SB, England JD, Hess RL, DaCosta J (1980) Effects of acute changes in blood glucose on $\mathrm{HbA}_{1 \mathrm{c}}$. Diabetes 29: 623-629

21. Menard L, Dempsey ME, Blankstein LA, Aleyassine H, Wacks M, Soeldner JS (1980) Quantitative determination of glycosylated hemoglobin $A_{1}$ by agar gel electrophoresis. Clin Chem 26: 1598-1602

22. Beacom R, Sawnhey B, Kennedy L (1983) Peripheral nerve function in Type 1 (insulin-dependent) diabetic patients with limited joint mobility. Diabetologia 25: 139 (Abstract)

23. Yue DK, McLennan S, Delbridge L, Handelsman DJ, Reeve T, Turtle JR (1983) The thermal stability of collagen in diabetic rats: correlation with severity of diabetes and non-enzymatic glycosylation. Diabetologia 24: 282-285

24. Lubec G, Pollack A (1980) Reduced susceptibility of non-enzymatically glycosylated glomerular basement membrane to proteases. Renal Physiol 3: 4-8

25. Hodge JE (1955) The Amadori rearrangement. Adv Carbohydr Chem 10: 169-205

26. Reynolds TM (1965) Chemistry of nonenzymic browning II. Adv Food Res 14: 167-283

27. Koenig RJ, Peterson CM, Jones RL, Sandek C, Lehrman H, Cerami A (1976) Correlation of glucose regulation and hemoglobin $A_{1 c}$ in diabetes mellitus. $N$ Engl J Med 295: 417-420

28. Ditzel J, Kjaergaard J (1978) Haemoglobin $A_{1 c}$ concentrations after initial insulin treatment for newly discovered diabetes. $\mathrm{Br}$ Med $\mathrm{J} 1: 741-742$

Received: 11 June 1984

and in revised form: 16 October 1984

Dr. L. Kennedy

Sir George E. Clark Metabolic Unit

Royal Victoria Hospital

Belfast BT12 6BA

Northern Ireland 